\title{
DESAIN INTERNET OF THINGS (IoT) UNTUK OPTIMASI PRODUKSI PADA AGROINDUSTRI KARET
}

\author{
Muhamad Bahrul Ulum \\ Program Studi Teknik Informatika, Fakultas Ilmu Komputer, Universitas Esa Unggul \\ Jl. Arjuna Utara No.9 Kebon Jeruk, Jakarta Barat, 11510 \\ E-mail : m.bahrul_ulum@esaunggul.ac.id
}

\begin{abstract}
ABSTRAK
Karet merupakan komoditas yang sangat penting di Indonesia, karena devisa negara yang dihasilkan dari komoditas karet ini cukup besar. Dalam MP3EI (Master Plan Percepatan dan Perluasan Pembangunan Ekonomi Indonesia) 2011 - 2025 (Kemenko Ekon 2011) dinyatakan bahwa perkebunan karet termasuk ke dalam kegiatan ekonomi utama di Indonesia dan difokuskan pada koridor ekonomi Sumatera sebagai daerah penghasil utama karet sebesar 63\%. Indonesia seperti halnya Thailand dan Malaysia tergabung dalam International Tripartite Rubber Council (ITRC) karena ketiga negara tersebut pada saat pembentukannya pada tahun 2001 merupakan penghasil karet alam terbesar. Penelitian ini bertujuan mendesain internet of things (IoT) untuk optimasi produk pada agroindustri karet. Setiap produksi karet bisa dipantau menggunakan sensor yang terhubungan dengan PC untuk mencatat setiap jumlah produksi yang dihasilkan pohon karet. Dengan demikian terdapat pencatatan pada database secara cepat dan tepat untuk menentukan langkah-langkah produksi secara efektif sehingga dapat meningkatkan produksi karet. Hasil penelitian didapat rancangan awal berupa desain internet of things (IoT) untuk optimasi produksi pada agroindustri karet. Nantinya setiap produksi karet bisa dipantau menggunakan sensor yang terhubungan dengan PC untuk mencatat setiap jumlah produksi yang dihasilkan pohon karet. Dengan demikian terdapat pencatatan pada database secara cepat dan tepat untuk menentukan langkah-langkah produksi secara efektif sehingga dapat meningkatkan produksi karet.
\end{abstract}

Kata Kunci: Agroindustri, Internet of Things, Karet.

\section{PENDAHULUAN}

Karet merupakan komoditas yang sangat penting di Indonesia, karena devisa negara yang dihasilkan dari komoditas karet ini cukup besar. Dalam MP3EI (Master Plan Percepatan dan Perluasan Pembangunan Ekonomi Indonesia) 2011 - 2025 (Kemenko Ekon 2011) dinyatakan bahwa perkebunan karet termasuk ke dalam kegiatan ekonomi utama di Indonesia dan difokuskan pada koridor ekonomi Sumatera sebagai daerah penghasil utama karet sebesar $63 \%$.

Seperti halnya Thailand dan Malaysia, Indonesia tergabung dalam International Tripartite Rubber Council (ITRC) karena ketiga negara tersebut pada saat pembentukannya pada tahun 2001 merupakan penghasil karet alam terbesar. Thailand menjadi negara penghasil karet alam terbesar dengan produksi karet pada tahun 2015 sebesar 4.473 juta ton, sementara Indonesia di peringkat kedua dengan produksi karet pada periode yang sama sebesar 3.1754 juta ton kemudian disusul oleh Vietnam dengan produksi 1.017 juta ton pada periode yang sama.

Ditinjau dari sisi luas, Indonesia memiliki lahan kebun karet terluas di dunia yaitu 3.4 juta ha. Dengan demikian, produktivitas kebun karet Indonesia masih sangat rendah yaitu sebesar 1.036 ton/ha/tahun dibandingkan dengan Thailand sebesar 1.4 ton/ha/tahun. Kebun karet di Indonesia sebagian besar (85\%) dimiliki rakyat dan pengelolaannya masih belum dilakukan secara optimal sehingga berpengaruh terhadap produktivitas kebun karet nasional yang masih rendah (Kementan 2015). Agar komoditas karet dapat tetap bersaing di pasar domestik maupun internasional dibutuhkan efisiensi dan efektifitas dalam pengelolaan manajemen produksi. Saat ini, untuk optimasi produksi pertanian dipengaruhi terhadap situasi - situasi tertentu seperti perkiraan cuaca atau lainnya lebih kritikal dibanding perluasan lahan. Untuk menghasilkan keputusan yang tepat petani membutuhkan data real time tentang operasi dan proses produksi. Salah satunya dengan pendekatan internet of things (IoT). Internet Of Things memungkinkan pengguna untuk mengelola dan mengoptimalkan elektronik dan peralatan listrik yang menggunakan internet.

Penelitian terkait dalam bidang agroindustri karet telah dilakukan, (Suharman $d k k, 2013)$, (Baihaqi, 2014), (Rugesty, 2014), (Marimin $d k k$. 2014), (Marizka $d k k$. 2015), (Teniwut, 2016) dan (Rukmayadi $d k k$. 2016). Tetapi penelitian-penelitian tersebut tidak mengkaji tentang aspek optimasi produk dalam proses bisnis agroindustri karet. Dari permasalahan di atas penelitian ini ditujukan untuk mendesain internet of things (IoT) untuk mengoptimasi produksi pada agroindustri karet. Setiap produksi karet bisa dipantau menggunakan sensor yang terhubungan dengan PC untuk mencatat setiap jumlah produksi yang dihasilkan pohon karet. Dengan demikian terdapat pencatatan pada database secara cepat dan tepat untuk menentukan langkah-langkah produksi 
secara efektif sehingga dapat meningkatkan produksi karet.

\section{RUANG LINGKUP}

Dalam penelitian ini permasalahan mencakup:

1. Mendesain internet of things (IoT) untuk mengoptimasi produksi

2. Setiap produksi karet bisa dipantau menggunakan sensor yang terhubungan dengan PC untuk mencatat setiap jumlah produksi yang dihasilkan pohon karet.

\section{BAHAN DAN METODE}

Berikut disajikan bahan dan metode yang terkait dengan penelitian ini

\subsection{Internet of Things (IoT)}

Internet of Things (IoT) adalah paradigma inovatif yang membuat bumi dalam pengaturan telekomunikasi nirkabel modern dengan cepat. Kesan dasar dari konsep ini adalah perluasan Internet ke dunia nyata dengan mengambil benda-benda sehari-hari. Agen fisik tidak lagi terpisah dari dunia virtual tetapi dikendalikan dari jarak jauh bertindak sebagai titik kontak fisik ke layanan Internet (Talari $d k k, 2017)$.

Tantangan utama dalam IoT adalah menjembatani kesenjangan antara dunia fisik dan dunia informasi. Seperti halnya mengolah data yang diperoleh dari peralatan eletronik melalui sebuah interface antara pengguna dan peralatan itu. sensor mengumpulkan data mentah fisik dari skenario real time dan mengkonversikan ke dalam mesin format yang dimengerti sehingga akan mudah dipertukarkan antara berbagai bentuk format data. Pada gambar 1 contoh tentang beberapa koneksi berbasis IoT.

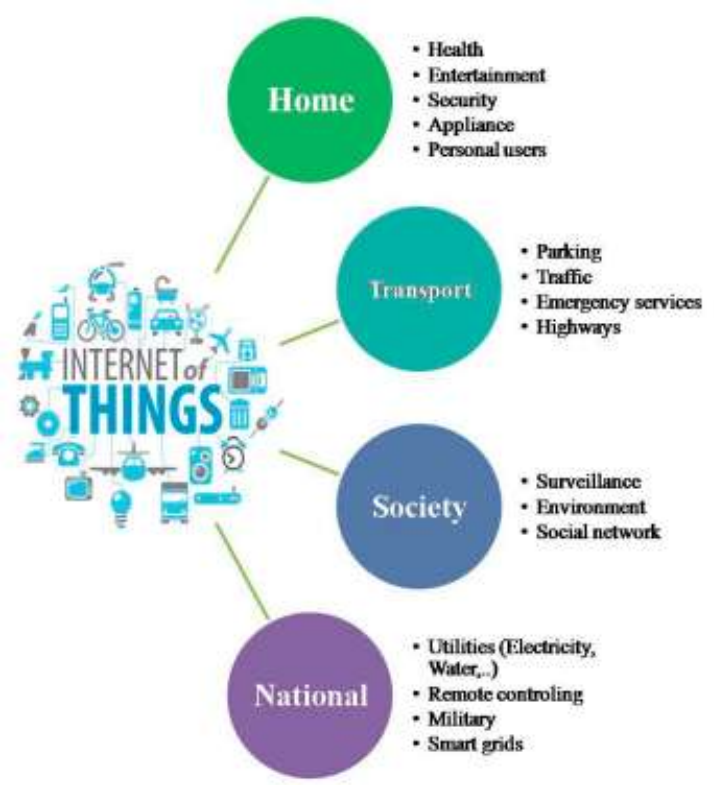

Gambar 1. Koneksi berbasis IoT

\subsection{Data Acquisition}

Data Acquisition (DAQ) adalah proses mengukur fenomena listrik atau fisik seperti tegangan, arus, suhu, tekanan, atau suara dengan komputer. Sebuah Sistem Data Acquisition terdiri dari sensor, perangkat keras pengukuran DAQ, dan komputer dengan software yang telah diprogram. Dibandingkan dengan sistem pengukuran tradisional, sistem Data Acquisition berbasis PC mengeksploitasi kekuatan pemrosesan, produktifitas, tampilan, dan kemampuan konektifitas komputer standar industri menyediakan solusi pengukuran yang lebih kuat, fleksibel, dan hemat biaya (Alfanz $d k k, 2016$ ). Gambar 2 adalah proses Data Acquisition.

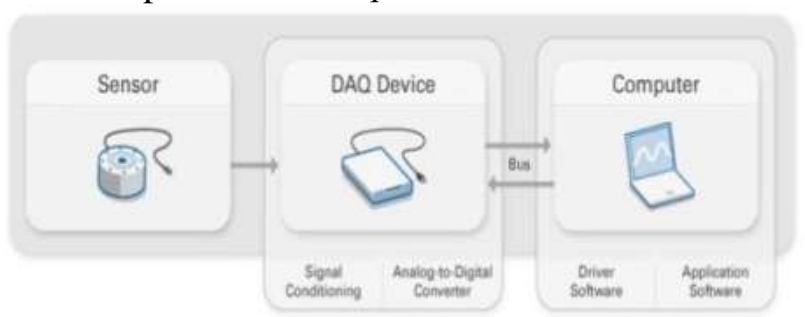

\section{Gambar 2. Diagram blok bagian sistem Data Acquisition}

\subsection{Agroindustri Karet}

Agroindustri mempunyai peranan penting dan potensial untuk mempercepat transformasi perekonomian dari struktur pertanian ke struktur industri. Salah satu agroindustri yang dapat dikembangkan di Indonesia adalah agroindustri yang berbasiskan tanaman karet. Tanaman karet merupakan produk unggulan sub-sektor perkebunan di Indonesia bersama kelapa sawit, kelapa, tebu, kakao, kopi, teh, tembakau dan kapas. Di sektor perdagangan, karet dan produk karet juga termasuk sepuluh komoditas utama yang diprioritaskan pengembangannya baik untuk pasar domestik maupun ekspor (Rukmayadi $d k k$. 2016).

Sejumlah lokasi di Indonesia memiliki keadaan lahan yang cocok untuk penanaman karet, sebagian besar berada di wilayah Sumatera dan Kalimantan. Luas area perkebunan karet tahun 2005 tercatat mencapai lebih dari 3.2 juta ha yang tersebar di seluruh wilayah Indonesia. Diantaranya $85 \%$ merupakan perkebunan karet milik rakyat, dan hanya $7 \%$ perkebunan besar negara serta $8 \%$ perkebunan besar milik swasta. Produksi karet secara nasional pada tahun 2005 mencapai 2.2 juta ton (www.bi.go.id).

\subsection{Metode}

Metode yang digunakan dalam penelitian ini merupakan metode pendekatan dari Cisco. Metode ini terdiri dari beberapa tahap, yaitu : Prepare, Plan, Design, Implement, Operate dan Optimize (PPDIOO). Berikut tahap-tahap PPDIOO pada gambar 3. 


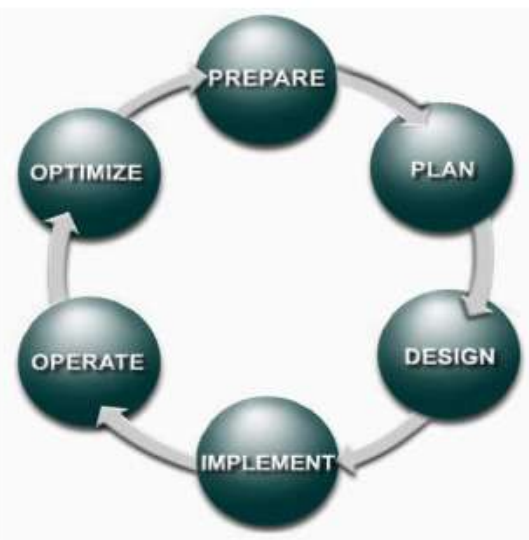

Gambar 3. Metode PPDIOO (Cisco, 2005)

1. Prepare

Tahap ini diawali dengan menganalisa situasional agroindustri karet dengan cara melakukan pengumpulan data dilakukan dengan survey lapangan yang ditujukan untuk memperoleh data primer dan memverifikasi model. Survey dilakukan dengan observasi, wawancara, dan pengisian kuesioner terhadap pengambil keputusan yang terkait dengan penelitian ini.

2. Plan

Tahap ini diawali dengan mengidentifikasi kebutuhan dan dilakukan pengumpulan data dari berbagai pihak yang terkait dalam produksi pada agroindustri karet.

3. Design

Kebutuhan awal yang telah ditentukan pada tahap Plan membentuk kegiatan desain arsitektur IoT untuk diimplementasikan pada agroindustri karet sebagai optimasi produksi.
4. Implement

Pada tahap ini adalah tahap implementasi dan verifikasi dimulai setelah desain telah disetujuai. Jaringan dan komponen tambahan yang dibangun sesuai dengan spesifikasi desain.

5. Operate

pengujian akhir dari kesesuaian desain. Pada tahap ini dilakukan pemeliharaan jaringan melalui pemantauan sehari-hari, yang mungkin termasuk memelihara ketersediaan dan mengurangi biaya. Deteksi kesalahan, perbaikan, dan pemantauan kinerja dapat memberikan data untuk tahap pengoptimalan jaringan.

6. Optimize

Tahap optimize didasarkan pada manajemen jaringan proaktif, tujuannya adalah untuk mengidentifikasi dan memecahkan masalah sebelum masalah nyata timbul. Deteksi kesalahan dan perbaikan (pemecahan masalah) yang diperlukan saat manajemen proaktif tidak dapat memprediksi dan mengurangi kesalahan.

\section{ARSITEKTUR DAN DESAIN SISTEM}

Tahap desain sistem memiliki tujuan untuk mengubah model informasi yang telah dibuat selama tahapan analisis menjadi model yang sesuai dengan teknologi yang akan dipergunakan untuk implementasi sistem.

Arsitektur umum aplikasi IoT dapat dibagi menjadi tiga lapisan: lapisan penginderaan, lapisan transport dan lapisan aplikasi. arsitektur semacam ini cukup jelas dan fleksibel untuk sistem pemantauan kami, sehingga kami merancang arsitektur sistem berdasarkan model umum tersebut. gambar 4 menunjukkan Desain Arsitektur Internet of Things untuk Agroindustri Karet.

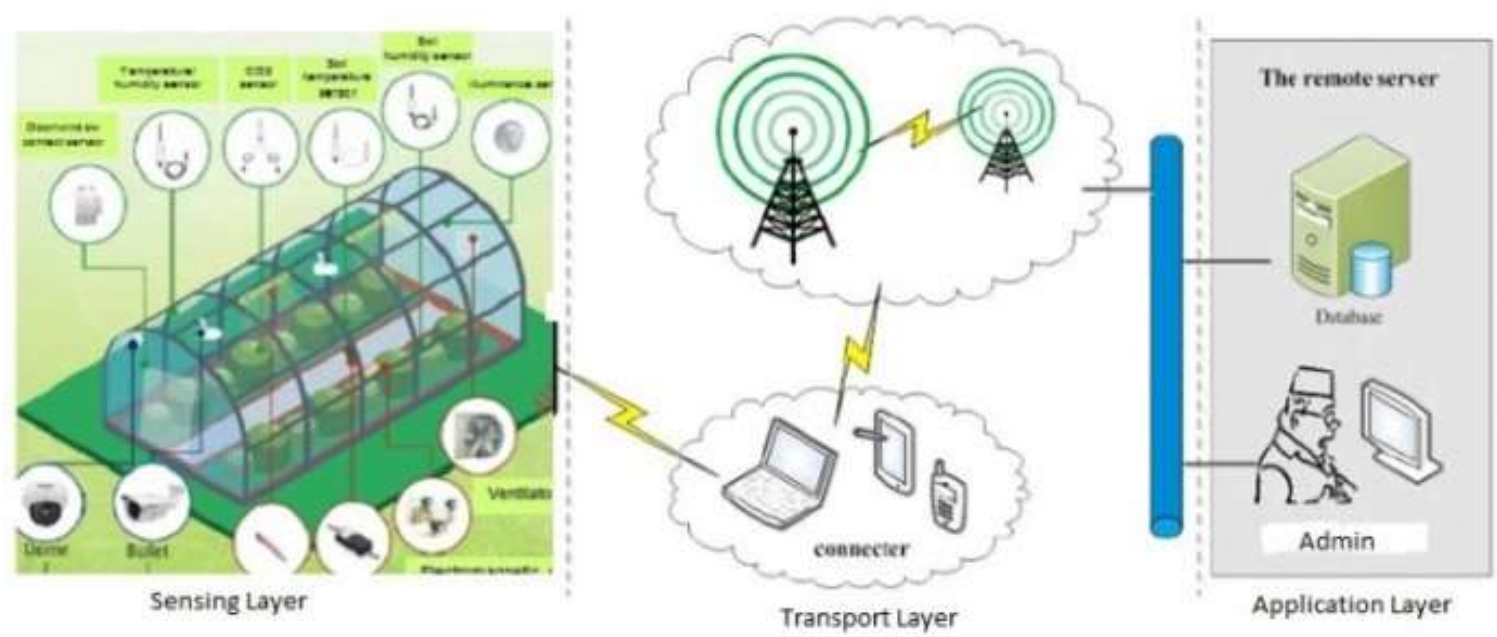

Gambar 4. Desain Arsitektur Internet of Things untuk Agroindustri Karet 
Optimasi produk dipengaruhi situasi-situasi tertentu seperti perkiraan cuaca, keadaan tanah, dan kebutuhan pasar terhadap tanaman tertentu. Untuk menghasilkan keputusan yang tepat petani membutuhkan data real-time tentang kondisi cuaca saat itu.

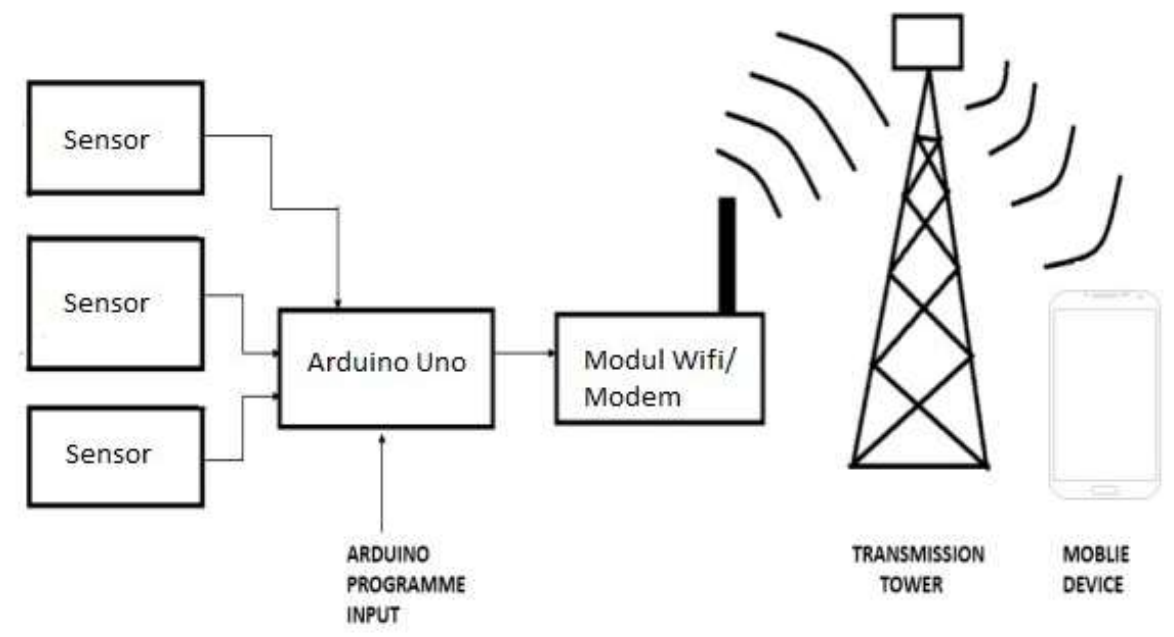

Gambar 5. Blok Diagram

Seperti yang ditunjukkan pada gambar 5 yaitu sistem terdiri dari tiga sensor yang datanya dikumpulkan oleh Arduino. Arduino mengirim data yang dikumpulkan ke wifi/modem dan wifi/modem mengirim data ke ponsel pengguna melalui jaringan menggunakan kartu SIM. Sistem bisa beroperasi secara otonom setelah koneksi telah dibuat dan program telah diunggah ke Arduino. Sistem ini tidak membutuhkan manual input selama operasi sehingga dapat digunakan di remote area dengan pemantauan manual tanah dan parameter air irigasi.

Setiap produksi karet bisa dipantau menggunakan sensor yang terhubungan dengan PC untuk mencatat setiap jumlah produksi yang dihasilkan pohon karet. Dengan demikian terdapat pencatatan pada database secara cepat dan tepat untuk menentukan langkahlangkah produksi secara efektif sehingga dapat meningkatkan produksi karet. Sehingga dengan terkoneksinya perangkat dan tersedianya database yang terhubung secara real time antar stakeholder untuk menentukan kebijakan untuk optimalisasi produksi pada agroindustri karet, serta dapat dijadikan sebagai bahan pertimbangan bagi pengusaha (sektor swasta) dalam rangka pelaksanaan investasi pada sektor agroindustri karet.

\section{KESIMPULAN}

Berdasarkan hasil penelitian didapat rancangan awal berupa desain internet of things (IoT) untuk optimasi produksi pada agroindustri karet. Nantinya setiap produksi karet bisa dipantau menggunakan sensor yang terhubungan dengan PC untuk mencatat setiap jumlah produksi yang dihasilkan pohon karet. Dengan demikian terdapat pencatatan pada database secara cepat dan tepat untuk menentukan langkah-langkah produksi secara efektif sehingga dapat meningkatkan produksi karet

\section{SARAN}

Dibuat prototipe internet of things (IoT) untuk optimasi produksi pada agroindustri karet, sehingga setiap produksi karet bisa dipantau menggunakan sensor yang terhubungan dengan PC untuk mencatat setiap jumlah produksi yang dihasilkan pohon karet.

\section{DAFTAR PUSTAKA}

Alfanz, R., Nurhadi, A., \& Laksmono, J. A. 2016. Perancangan dan Implementasi Sistem Monitoring Produksi Biogas pada Biodigester. Jurnal Nasional Teknik Elektro, 5(1), 128-134.

Baihaqi. 2014. Analisis kelayakan lokasi dan finansial pembangunan industri pengolahan karet di pesisir Timur Provinsi Aceh. Agrisep. 15(1):1-9.

Cisco. 2005. Creating Business Value and Operational Exellence withthe Cisco Systems Lifecycle Services Approach.

[Kemenko Ekon] Kementerian Koordinator Bidang Perekonomian. 2011. Masterplan Percepatan dan Perluasan Pembangunan Ekonomi Indonesia. Jakarta (ID): Kementerian Koordinator Bidang Perekonomian Republik Indonesia.

[Kementan] Kementerian Pertanian. 2015. Area, produksi dan hasil perkebunan di Indonesia, 2011 2015. Jakarta (ID): Direktorat Jenderal Perkebunan, Kementerian Pertanian Republik Indonesia.

Marimin, Machfud, Martini S, Rukmayadi D, Wiguna B, Putra MPIF, Adhi W. 2015. Teknik dan Aplikasi 
Produktivitas Hijau (Green Productivity) pada Agroindustri. Bogor (ID): IPB Press.

Marizka DA, Djatna T, Arkeman Y. 2015. A Model of green value stream mapping for rubber based automotive products. Scientific J PPI-UKM. 2(1):17-23.

Rugesty Y. 2014. Analisis arah kebijakan dan strategi pengembangan agribisnis karet rakyat dalam perspektif peranan kelembagaan dan ekonomi wilayah di Provinsi Sumatera Selatan [tesis]. Bogor (ID) :Sekolah Pascasarjana Institut Pertanian Bogor.

Rukmayadi, D., Marimin, M., Haris, U. and Yani, M., 2016. Rubber Agro-Industry Green Logistic Conceptual Model. International Journal of Supply Chain Management, 5(3), pp.192-204.

Talari, S., Shafie-Khah, M., Siano, P., Loia, V., Tommasetti, A. and Catalão, J., 2017. A review of smart cities based on the internet of things concept. Energies, 10(4), p.421.

Suharman, Sukardi, Honggokusumo S, Suryani A. 2013. Analisis potensi pengembangan industri barang jadi karet di Sumatera Selatan. J Ris Ind. 7(3):173-262.

Teniwut YK. 2016. Sistem pendukung pengambilan keputusan cerdas spasial peningkatan produktivitas agroindustri karet dengan pendekatan produktivitas hijau. Program Studi Teknologi Industri Pertanian [tesis]. Bogor (ID): Sekolah Pascasarjana Institut Pertanian Bogor. 